\title{
En medio de la violencia: recursos, tácticas y violencia contra el sector ganadero*
}

DOI: https://doi.org/10.18046/recs.i28.3199

\author{
In the Midst of Violence: Resources, Tactics and Violence \\ against the Livestock Sector \\ No meio da violência: recursos, táticas e violência \\ contra o setor pecuário
}

\author{
Alejandro Ponce de León-Calero ${ }^{* *}$ \\ University of California (Davis, EE. UU.)
}

\begin{abstract}
* Este artículo hace parte de una investigación sobre lógicas, dinámicas y modos de interacción entre grupos armados y población civil en contextos de violencia armada. La investigación fue desarrollada dentro del programa doctoral en Sociología de la Universidad de Texas en Austin, como requisito para completar el título de Máster. Por su lectura atenta y sus comentarios oportunos, agradezco a Luis Fernando Barón, Javier Auyero, Michael P. Young, María Emma Wills, Riad Azar, Michael Findley, Oliver Kaplan y Carmen Gutiérrez; a los miembros del Urban Ethnography Lab de la Universidad de Texas en Austin, y a los pares evaluadores de este texto. Artículo de investigación recibido el 20.07.2018 y aceptado el 21.11.2018.
\end{abstract}

** Correo electrónico: poncedeleon@ucdavis.edu ORCID: https://orcid.org/oooo-ooo2-4808-3373 


\section{Cómo citar/How to cite}

Ponce de León-Calero, Alejandro (2019). En medio de la violencia: recursos, tácticas y violencia contra el sector ganadero. Revista CS, 28, 19-45. https://doi.org/10.18046/recs.i28.3199 
Resumen

Abstract

Resumo

En este artículo se presentan los resultados de una investigación sobre las relaciones entre ganaderos y grupos armados, en torno a la captación forzosa de recursos económicos, de acuerdo a los testimonios y las memorias de los ganaderos. Se recurrió a metodologías de análisis tanto estadístico como de las narrativas, a fin de explorar los patrones de y las disposiciones en las interacciones con los grupos armados, respectivamente. Como se sostiene, los ganaderos, más que simpatizantes o víctimas pasivas, actuaron de manera estratégica a la hora de tomar decisiones, recurrir a capitales sociales y económicos, para así negociar los términos de su propia sujeción. En el marco de los estudios sobre la rememoración e historización de los pasados violentos en Colombia, el artículo hace énfasis en la necesidad de comprender los contextos locales-en su incertidumbre, cambio y constante reajuste-. También se invita a romper con aquellos hábitos de pensamiento que reducen los vínculos entre población y grupos armados a simples cálculos económicos y políticos, los cuales, se sostiene, emergen de la práctica cotidiana y la preocupación por el mantenimiento de la vida misma.

PALABRAS CLAVE:

conflicto armado, recursos económicos, población civil, ganadería

This article discusses the main results of a research study on the interactions between stockbreeders and armed groups in relation to the illegal collection of funds, as narrated in the stockbreeders' testimonies and memories. The paper relies on both statistical and narrative analysis methodologies in order to explore the patterns and configurations in interactions with armed groups. It is argued here that the stockbreeders were not supporters or passive victims, rather they acted strategically when making decisions and relying on social and financial capitals actors to negotiate the terms of their own subjugation. Drawing upon studies on remembrance and historicization of the Colombian armed conflict, the paper stresses the need to understand local contexts, taken as spaces of uncertainty, agitation, and ongoing readjustment. The paper also cautions scholars 
against the tendency to reduce the interactions between civilians and armed groups to mere economic or political motivations. Rather, these interactions are considered to emerge mainly from individuals' everyday concerns and the desire to protect their lives.

\section{KEYWORDS:}

Armed Conflict, Economic Resources, Civilians, Livestock

Este artigo apresenta os resultados de uma investigação sobre as relações entre agricultores e grupos armados, em torno do recrutamento forçado de recursos econômicos, segundo os depoimentos e memorias dos agricultores. Foram usadas metodologias de análise estatística e narrativa para explorar padrões e disposições nas interações com grupos armados respectivamente. Como o argumentado, os agricultores, em vez de simpatizantes ou vítimas passivas, agiram estrategicamente ao tomar decisões, recorrendo ao capital social e econômico para negociar os termos de sua própria sujeição. No âmbito dos estudos sobre a memória e historicização dos passados violentos na Colômbia, o artigo enfatiza a necessidade de compreender os contextos locais- em sua incerteza, mudança e reajuste constante-. Também convida-se a romper com esses hábitos de pensamento que reduzem os vínculos entre população e grupos armados a simples cálculos econômicos e políticos, os quais, argumenta-se, emergem da prática cotidiana e da preocupação com a manutenção da própria vida.

\section{PALAVRAS-CHAVE:}

conflito armado, recursos econômicos, população civil, pecuária 


\section{Introducción}

La violencia armada ha marcado la vida de Diana Garzón ${ }^{1}$. Ella recuerda que de niña solía escuchar a los empleados de la finca hablar sobre las masacres que ocurrían en regiones vecinas. Eso era algo que "(en su pueblo) no pasaba", pues, a diferencia de los municipios al norte del departamento, aquellos en el suroriente del Huila eran un territorio de relativa paz a mediados del siglo XX. Sin embargo, las cosas empezaron a cambiar durante los setenta (Programa de las Naciones Unidas para el Desarrollo (PNUD) Colombia, 2010). Primero fueron los guerrilleros del M-19 quienes empezaron a extorsionar a quienes concentraran algún tipo de riqueza, incluida la familia Garzón. Se pagaba la cantidad demandada y nadie resultaba herido. Cuando no se podía pagar, los guerrilleros retenían el ganado hasta que se hiciera el pago. Con el tiempo, las FARC tomaron el control de la zona e impusieron nuevas condiciones para quienes se negaran a pagar su "impuesto guerrillero". Diana recuerda que su sobrino fue brutalmente golpeado con la culata de un rifle; su tío fue asesinado camino a la finca; los guerrilleros secuestraron a varios de sus vecinos y amigos. Algunos pudieron regresar, otros no.

En 1989, Iván Márquez, quien había sido amigo de la familia en otros tiempos, ordenó el secuestro de la madre de Diana, doña Clara, exigiendo una suma imposible de pagar. Eran tiempos difíciles para la familia y la gravedad de la situación obligó a Diana a "dejar los sentimientos bien guardados en la casa, e ir a negociar como un salvaje". Primero, vendió algunos animales, y con dinero en mano intentó negociar la suma. Los guerrilleros no aceptaron la propuesta. Diana intentó renegociar varias veces sin mucho éxito, hasta que habló con algunos políticos y líderes locales, quienes mediaron por ella. "No se preocupe doña", le dijo un guerrillero a su madre durante el cautiverio, "que por usted ha hablado gente muy importante". La suma final era significativamente más baja. Doña Clara fue liberada el 4 de marzo de 1990.

La historia de Diana ilustra bien las dinámicas detrás de la captación forzosa de recursos en el marco del conflicto armado colombiano. Con base en los relatos y testimonios de ganaderos, quienes declararon ser víctimas del conflicto armado ${ }^{2}$, este artículo explora las lógicas y tácticas que emplearon a fin de dar respuesta a las demandas de los actores armados. La investigación se enfoca en el gremio ganadero, pues, como se ha insistido en un número importante de estudios sobre la confrontación armada reciente, los crímenes de orden económico contra los miembros del

1. Algunos nombres de las personas y lugares aquí mencionados han sido cambiados para proteger la identidad de sus verdaderos protagonistas.

2. Ganadero aquí se entiende como aquella persona que posea de una cabeza de ganado en adelante. 
sector primario fueron un elemento dinamizador a la conformación de autodefensas y grupos paramilitares en Colombia (Gutiérrez-Sanín y Vargas, 2017; Romero, 2002).

Si bien las alianzas entre las organizaciones armadas y los líderes gremiales han sido documentadas (Ronderos, 2014), poco se sabe sobre las interacciones cotidianas que ocurrieron alrededor de la captación forzosa de recursos. Igualmente, solo un reducido número de estudios se han interesado en la manera en que las personas que fueron victimizadas debido a la actividad económica que desempeñaban, dan sentido a los pasados violentos y a su participación en ellos (Barón, 2016). Trabajos recientes han insistido en que los términos de la interacción entre la población civil y los grupos armados es un factor determinante en la variación de la violencia en contextos de confrontación armada (Arjona, 2015; Kaplan, 2017).

Como se sostiene en el presente artículo, los ganaderos, más que simpatizantes o víctimas pasivas, actuaron de manera estratégica al momento de tomar decisiones o recurrir a capitales sociales, culturales y económicos para negociar los términos de su propia sujeción. Sin embargo, cómo y qué tácticas podían utilizar dependía de qué y cuántos recursos tenían a disposición. Los ganaderos que no contaban con recursos o dependían de economías frágiles declararon ser víctimas de violencia contra su integridad o forma de vida en mayores proporciones que aquellos con más recursos, los cuales pudieron entablar complejas estrategias de cooperación con los actores armados y así salvaguardar sus predios, sus vidas y las de sus seres cercanos.

Esto responde a que, con base en los testimonios aquí analizados, sobrevivir a una guerra requería, ante todo, de soluciones prácticas. Como se verá a continuación, el desenlace de la captación forzosa de recursos dependió no solo de lo pasional o lo inesperado, lo discursivo o lo narrativo, sino de lo circunstancial, lo pragmático y lo cotidiano; aquello que varios autores -como Primo Levi (2005)- han llamado "la zona gris" de la violencia ${ }^{3}$. Ante los estudios del pasado reciente y la memoria histórica de la confrontación armada en Colombia, este artículo sugiere que, al enfocar el análisis en los entramados sociales donde la violencia se produce, las texturas narrativas y vivenciales siempre han de exceder y problematizar las categorías y modelos analíticos (víctima y victimario, eventualidad y normalidad, etc.) con las cuales reconstruimos, politizamos y sacralizamos ciertos tipos de memoria histórica (Aparicio, 2016; Jaramillo Marín, 2014; Sánchez, 2018; Serna Dimas, 2012).

Contra los estudios que reducen a los empresarios del sector primario a perpetradores o financiadores de la guerra, es importante recordar que varios estudios previos

3. En el contexto argentino, Javier Auyero (2007) presenta una muy interesante discusión sobre la producción social de la violencia, la cual deja entrever los complejos andamiajes que dieron fruto a los saqueos a negocios y supermercados en diciembre de 2001 en Argentina. Aquí, la violencia no es un evento que rompe con lo ordinario, más bien es una manifestación de la política cotidiana y las formas de protesta social. 
han señalado que el vínculo entre la población civil y los grupos armados no siempre fue antecedido por una decisión racional, política o ética (Bolívar y Nieto, 2003; Uribe de Hincapié, 2001). Las memorias aquí estudiadas dan cuenta, ante todo, de un mundo terrible e indescifrable en el que, en medio de las sujeciones que "separa(n) y une(n) al mismo tiempo a los dos bandos de patrones y siervos" (Levi, 2005:498), los ganaderos siempre buscaron instancias de significación, creación, agencia, empoderamiento y contestación a fin de garantizar su vida y la de sus seres queridos.

El artículo se divide en tres secciones, además de una conclusión y la presente introducción. La primera sección se sitúa dentro de la discusión académica pertinente; seguidamente, se presenta la metodología empleada, las fuentes y el enfoque de la investigación; y en la tercera se ofrece un resumen de los principales resultados. En suma, el artículo demuestra que la captación forzosa es, en la memoria de los ganaderos, mucho más que una transacción económica o una decisión política. Por el contrario, es el producto de una compleja situación de interdependencia que exigía el reconocimiento y la acción recíproca entre ganaderos y actores armados a la hora de definir las cantidades, frecuencias y modos de extracción, así como las represalias por no cooperar con las directrices propias del orden beligerante.

\section{Recursos económicos, población civil y violencia armada}

Las relaciones entre grupos armados y población civil ha sido una preocupación trasversal a las ciencias sociales en Colombia desde sus inicios (Guzmán, Fals, y Umaña, 1962). En la antropología, esta relación ha sido examinada por un importante número de etnografías en los principales escenarios del conflicto armado (Blair, Grisales y Muñoz, 2009; Campuzano, 2013; Jimeno, Varela y Castillo, 2012; Madariaga, 2006; Ramírez, 2011; Uribe, 1992). De estos trabajos se ha aprendido que la pregunta del porqué de la confrontación armada, desde sus propias categorías analíticas implícitas (perpetradores y víctimas, desapariciones y homicidios, entre otras), suele resultar carente de sentido cuando es llevada al registro de lo cotidiano. Más que un punto de quiebre o un "evento", este cúmulo de trabajos etnográficos ha documentado cómo las más de seis décadas de confrontación armada, con sus distintas manifestaciones, han sido incorporadas y habitualizadas por las poblaciones en las zonas en conflicto. La guerra en Colombia, más que un clivaje social, fue convertida en un eje integral a la vida cotidiana (Espinosa, 2010).

Si bien la literatura antropológica ha documentado exhaustivamente patrones de interacción entre grupos armados y población civil, solo un reducido número de investigaciones se ha enfocado en las relaciones alrededor de los recursos económi- 
cos (Ramírez, 2011). En la ciencia política, por su parte, este tipo de vínculos ha sido estudiado a partir de la pregunta por las relaciones entre recursos y dinámicas de la violencia (Idrobo, Mejía y Tribin, 2014; Rettberg, Leiteritz, Nasi y Prieto, 2018). De igual manera, un grupo de estudios interdisciplinares se ha venido interesando, recientemente, por la complicidad entre empresarios y actores armados (Sánchez León et al., 2018). Si bien estos esfuerzos han querido entender el impacto de los recursos económicos en la comisión de violaciones de derechos humanos, no son muchos los trabajos que han documentado las interacciones cotidianas, tales como la captación forzosa y extorsiva de recursos económicos, donde la población civil y los actores armados entraron a fin de evitar o reducir el uso de formas de violencia directa.

Este descuido analítico se hace aún más evidente en los estudios que abordan la relación entre el conflicto armado y el sector ganadero, los cuales han privilegiado el análisis de los grandes ganaderos en su papel de élites locales (Gutiérrez-Sanín y Vargas, 2017; Romero, 2000; Ronderos, 2014) o de empresarios rurales (Hristov, 2014; Sarmiento y Aviles, 2012), reduciendo la experiencia del pequeño y mediano ganadero a la del peón o aparcero. De aquí que en la literatura haya surgido una imagen de la ganadería como una actividad necesariamente destructiva, premoderna, ineficiente y represiva. Sin embargo, la ganadería, lejos de ser una actividad monolítica, es un mosaico complejo compuesto por importantes diferencias regionales, que excede los márgenes del campo económico (Flórez-Malagón, 2008; Van Ausdal, 2009). En Colombia, se estima que el $44 \%$ de los hatos ganaderos cuentan con menos de diez animales -lo mínimo para sobrevivir en condiciones de subsistencia- $y$, como se arguye aquí, aquellos que ejercieron su actividad económica en medio de la confrontación armada fueron, además, víctimas de crímenes y violaciones a los Derechos Humanos.

En el presente hay un gran vacío en la literatura nacional sobre cómo, por ejemplo, los "ganaderos de a pie" lograron sobrevivir ante la presencia de los actores armados, o cómo sus tácticas de supervivencia variaron de las de aquellos que contaban con más recursos ${ }^{4}$. Responder este tipo de vacíos no solo permitiría reconocer los distintos matices y contextos detrás de la captación de recursos, sino que, además, ayudaría a entender cómo y en qué medida las acciones cotidianas de la población

\footnotetext{
4. Esto no deja de ser paradójico, pues la violencia contra los ganaderos suele ocupar un papel central en varios de los mitos fundacionales de los grupos armados. Por ejemplo, las guerrillas comunistas justifican su rearme en 1960 luego de que Charro Negro fuese asesinado tras el robo de un ganado en el Cauca; en el discurso de apertura en la mesa del Caguán, Marulanda Vélez exigió una reparación por las "fincas, ganados, cerdos y aves de corral" que el Estado le expropió durante la operación Marquetalia; alias Cadena, carnicero de profesión, fue escolta de un ganadero antes de ser miembro del Bloque Montes de María; de igual modo, las víctimas de El Salado aseguran que la masacre de 2000 fue motivada por el robo de un ganado a la empresaria Enilce López
} 
civil pudieron aminorar el flagelo del actuar armado. Igualmente, documentar estas diferencias es una contribución fundamental a los modelos explicativos en la comprensión de los diferentes patrones espaciales y temporales de la violencia armada en Colombia, pues, como señala la literatura para otros casos de estudio, la disponibilidad de recursos es una variable determinante en el curso de una guerra (Collier, Hoeffler y Rohner, 2009; Collier y Sambanis, 2005; Hazen, 2013). Explorar las maneras en que los ganaderos y las fuerzas beligerantes interactuaron en el tiempo también permite entender la coproducción de los órdenes locales en que se han venido rastreando los efectos del actuar ganadero en la comisión de actos de violencia contra el resto de la población civil.

Finalmente, este trabajo, además de responder a lo que se cree un imperativo en el análisis de los pasados violentos en Colombia, espera contribuir a la discusión sobre las maneras en que estos llegan a ser evocados. La investigación partió de una cierta desazón ante los procesos actuales de construcción de una memoria histórica sobre la violencia que, al privilegiar los eventos de fractura, división y desgarramiento social (Sánchez, 2003), se han desinteresado por el espacio de lo cotidiano y sus instantes de la creación, agencia, empoderamiento y contestación. Si bien es un imperativo ético recuperar el pasado y así dignificar a las víctimas de delitos atroces, aquella fijación reciente con el dolor y el sufrimiento ajeno también ha llevado a que, en las maneras en que socialmente se invoca la memoria histórica, se caiga en lugares comunes, historicismos, en la sacralización de un tipo de memorias institucionales y, más peligrosamente, en la reducción de la confrontación armada al evento de quiebre, así como su "necesaria" re-estructuración económica y política (Aparicio, 2016).

Como lo han sugerido algunos trabajos anteriores, la guerra en Colombia ha sido un proceso social que ha articulado múltiples capas de acción y significación a lo largo de varias décadas (Uribe de Hincapié, 2001; Prieto Sanabria, 2012). Por ende, al enfocarse en las complejidades detrás de los acontecimientos bélicos y dar cabida analítica a la pluralidad de relatos y experiencias, este artículo insiste en la necesidad de reconocer las complejas imbricaciones en que ocurre la violencia armada en Colombia.

\section{Metodología}

La información en la que se fundamenta este artículo proviene de una encuesta implementada por la Federación Colombiana de Ganaderos (Fedegán) a ganaderos que declararon ser víctimas del conflicto armado de acuerdo con lo estipulado por 
la Ley 1448 de $2011^{5}$. A fin de ampliar sobre los patrones regionales, la investigación fue complementada con 53 entrevistas a profundidad realizadas, en el año 2013, a ganaderos de diferentes regiones de Colombia, como parte del acompañamiento legal brindado por el Observatorio de Derechos Humanos y Derecho Internacional Humanitario de dicha institución. La recolección de datos ocurrió en dos etapas. En la primera (2011), Fedegán distribuyó folletos informativos sobre la Ley 1448 de 2011 en todos los predios en los cuales se vacunó contra la fiebre aftosa (97\% de los predios ganaderos en el territorio colombiano). Si el ganadero estaba interesado, podía contactarse con las oficinas centrales de Fedegán llenando y enviando un formulario. En total, se recibieron más de 22000 formularios. En la segunda etapa (2012), un equipo de asesores legales contactó telefónicamente a los ganaderos interesados con el fin de completar una encuesta con la cual recolectaba información básica sobre los hechos y un testimonio libre acerca de lo ocurrido. En total, se completaron 4129 encuestas en las cuales se documentaron cerca de 7000 hechos de violencia en las principales regiones de producción ganadera del país entre de 1950 y 2012 (ver Mapa 1) ${ }^{6}$.

El trabajo investigativo partió de la siguiente pregunta: ¿qué tipo de relaciones se construyeron entre los ganaderos y los actores armados respecto a la captación forzada de recursos económicos? Por un lado, la investigación se interesó por la manera en que los ganaderos desempeñaban su actividad productiva e interactuaban con los actores armados en un contexto marcado por el riesgo, la amenaza y la muerte. Por el otro, se buscó construir una tipología de las tácticas empleadas por los ganaderos y entender su relación con la disponibilidad de recursos económicos. El estudio de los relatos y los resultados de la encuesta fue de orden cualitativo y cuantitativo7. Para ello, se recurrió a metodologías de análisis tanto estadístico como de las narrativas.

5. Esta ley, mejor conocida como la Ley de Víctimas y Restitución de Tierras, es el marco normativo que reglamenta las medidas de atención, asistencia y reparación integral a las víctimas del conflicto armado en Colombia y tendrá vigencia hasta junio de 2021. Al momento, se estima que menos del $10 \%$ de las víctimas del conflicto han sido reparadas en el transcurso de los últimos ocho años.

6. Los testimonios son recapitulaciones libres de hechos ocurridos, en algunos casos, varias décadas atrás. Debido a la naturaleza e intencionalidad de la encuesta, no hay forma de corroborar los hechos relatados. Si bien se pudo haber recolectado mejor información, los resultados de la encuesta siguen siendo únicos en muchos aspectos. Ante todo, es la única fuente disponible que registra información sobre la ocurrencia de violencia armada contra el sector ganadero.

7. Para el análisis cuantitativo, se recurrió a una serie de datos de panel para el período 1990-2010, suministrados por Fedegán, el Ministerio de Defensa, el Centro Nacional de Memoria Histórica y el Centro de Estudios sobre Desarrollo Económico (CEDE) de la Universidad de los Andes. 


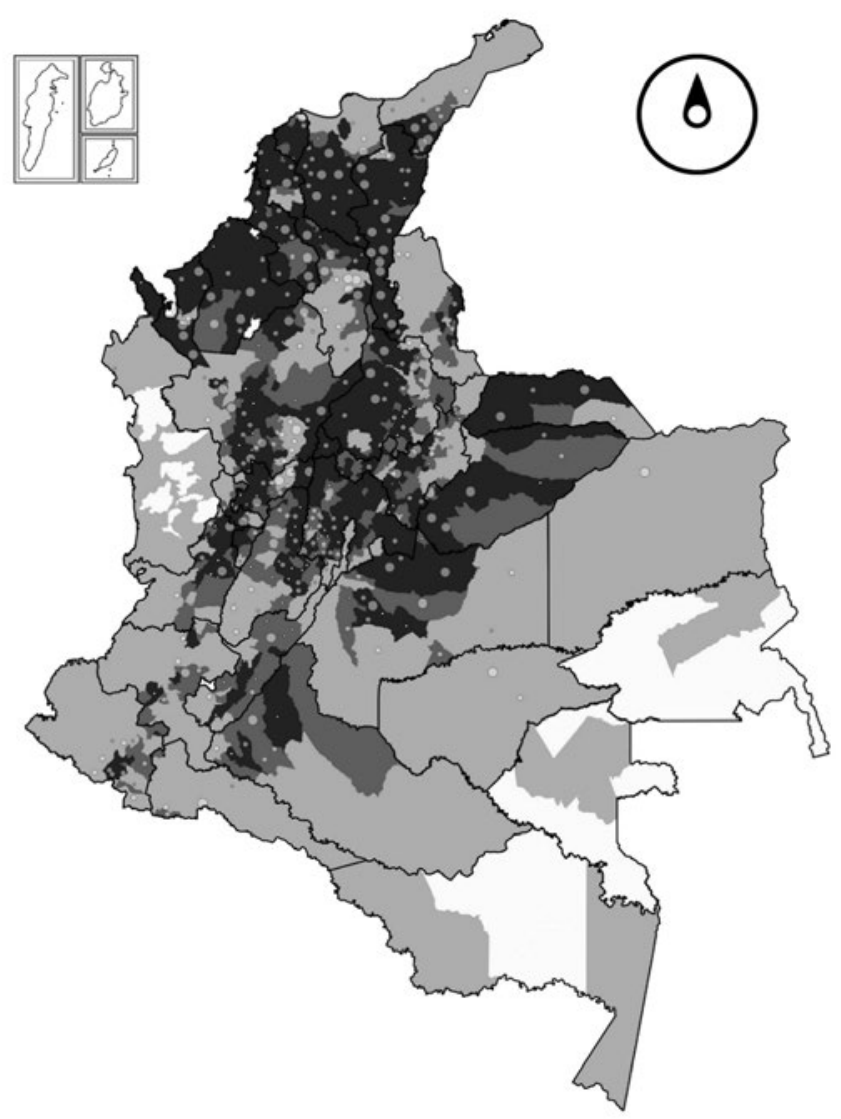

Número de animales por hectáreas

\section{Número de casos reportados}

$$
\text { - } 1-6
$$

Desde sus primeras etapas, la investigación adoptó un enfoque etnográfico al interesarse, ante todo, por la interpretación de los modos de vida en que cobran sentido las prácticas de los ganaderos. Con esto no se quiere dar a entender que el artículo es producto de una investigación etnográfica -como se ha referido al tra- 
bajo de campo en la antropología (Rees, 2018)-. Más bien, y queriendo contribuir a la conversación propia de la antropología colombiana sobre las relaciones entre grupos armados y población civil en los propios términos del campo académico, se ha seguido el llamado metodológico que hace Rosana Guber (2001: 12-16) al desglosar la etnografía en su triple acepción de enfoque, método y texto. Aquí, el enfoque etnográfico se entiende como un modo de reconfigurar el campo de visión e interpretación durante el análisis, lo cual responde a la necesidad de re-presentar de manera coherente los mundos sociales sobre los que se ha de dar cuenta. En cuanto al estudio de las memorias de los ganaderos, adoptar este tipo de enfoque exigió, más que cuestionar su veracidad o problematizarlas, abrir y participar en los mundos que emergen desde y dentro de estos testimonios. Investigaciones venideras deberán hacer un trabajo crítico; sin embargo, este tipo de investigaciones descriptivas son necesarias a la hora de entender la multiplicidad de experiencias vividas por los miles de víctimas que ha dejado el conflicto armado colombiano.

\section{“La violencia llegó...”}

Para muchos ganaderos, la confrontación armada fue algo que llegó y para lo que no estaban preparados. "Hoy en día se vive en relativa calma", afirma Santiago, un ganadero medio de Caldas, "pero (...) simplemente no sabés lo que puede pasar mañana". A mediados de los noventa, salir de la casa era una experiencia angustiosa para su esposa y él, pues a solo unos kilómetros de la finca las FARC y las AUC combatían por el control de la región del Magdalena Medio (Vásquez, 2006). "Sabías cuándo te ibas, pero no sabías si volverías". En Colombia, la población civil se vio profundamente afectada por la confrontación armada durante las últimas décadas del siglo XX (Grupo de Memoria Histórica, 2013). Varios ganaderos hablan de vivir en medio del fuego cruzado: eran reacios a tomar partido, había mucha incertidumbre sobre lo que estaba pasando y todos temían por sus propias vidas. Sus predios eran, en varios casos, los campos de batalla y, cuando los fusiles callaban, también se convertían en botines de guerra.

De acuerdo con los resultados de Fedegán, el $45 \%$ del total de los hechos criminales contra ganaderos registrados son atribuidos a los grupos guerrilleros, el 20\% a las AUC, y en un 35\% de los casos se desconoce el autor (al vivir bajo el yugo de varios grupos, no siempre es fácil determinar quién era de qué bando). Los principales crímenes reportados fueron el abigeato (hurto de ganado) y desplazamiento poblacional (individual y masivo). En cuanto a los crímenes de orden económico, los testimonios señalan que ambos grupos fueron igualmente responsables, teniendo 
en cuenta las importantes diferencias en su repertorio criminal. Mientras que el $74,5 \%$ de los secuestros y el $61 \%$ de las extorsiones registradas se le atribuyen a los grupos guerrilleros, el abigeato fue un crimen perpetrado mayormente por las AUC.

Como se puede ver en el Mapa 1, los crímenes se registraron en todas las regiones del país, con especial incidencia en aquellos municipios donde el hato ganadero era más cuantioso -principalmente en regiones donde prima la ganadería de carne-. A pesar de no haber podido encontrar diferencias espaciales significativas, sí se hallaron algunas temporales. Primero, la ocurrencia de crímenes contra los ganaderos tuvo un incremento entre 1997 y 2006 -período de escalamiento de la confrontación armada (Restrepo, Spagat y Vargas, 2003)-. El año con mayor número de crímenes reportados fue 2002, siendo el desplazamiento y el hurto de ganado los dos crímenes de mayor incidencia. Contrario a lo que se esperaba, la extorsión, el secuestro y el hurto no preceden a la conformación de las AUC. Por el contrario, aumentan significativamente durante su período de expansión y auge, siendo 1998 y el 2000 los años con mayor número de reportes. De igual forma, el desplazamiento tendía a aumentar significativamente en aquellos años en que las AUC llegaron por vez primera a un municipio, a pesar de que el desplazamiento tendía a ser precedido, en orden, por el reporte de casos de hurto de ganado, extorsión y amenaza.

A fin de identificar los factores que conducen a la victimización de los ganaderos, se estimaron cinco modelos estadísticos de efectos fijos ${ }^{8}$, utilizando datos de panel a nivel municipal (de 1993 a 2010). Como variable dependiente, se tomó el número de crímenes cometidos contra ganaderos, de acuerdo a la información recolectada por Fedegán. En los resultados, -que se encuentran en el Anexo 1-se puede advertir que los delitos contra los ganaderos ocurrieron en los municipios con mayor índice de ruralidad y en donde había un mayor número de cabezas de ganado. Igualmente, que hay una relación tanto positiva como significativa entre el secuestro y el desplazamiento de la población civil y los crímenes cometidos contra ganaderos. Esto indica que los patrones de criminalidad contra los ganaderos se asemejan a aquellos vividos por el resto de la población civil. Sin embargo, y de manera sorprendente, la tasa de homicidios parece no estar necesariamente asociada a la suma anual de crímenes cometidos contra ganaderos, mientras que el índice de conflicto sí. Esto puede sugerir, además, que los crímenes contra los ganaderos fueron cometidos principalmente en territorios en contienda y no necesariamente en aquellos de dominación beligerante -donde los patrones de violencia no solo siguen las lógicas

8. Un modelo de efectos fijos es un modelo estadístico en el que los parámetros del modelo son cantidades fijas o no aleatorias. Esta aproximación facilita el control de la heterogeneidad inobservada en el análisis de datos de panel, donde se cuenta con observaciones longitudinales para una misma unidad. 
económicas, sino también políticas y territoriales-, lo que explicaría que, más que un blanco militar, los ganaderos y sus fincas fueron un botín de guerra9.

No todos los ganaderos sufrieron el flagelo de la confrontación armada de la misma forma. Al desagregar los datos de acuerdo al tamaño del hato de los ganaderos ${ }^{10}$, se pueden advertir algunas diferencias. Si los grupos guerrilleros fueron responsables del $69 \%$ de los crímenes contra los grandes ganaderos (en su mayoría, extorsión y secuestro), los paramilitares tendían a atacar más a los pequeños ganaderos. Del mismo modo, estos últimos fueron amenazados tres veces más que los ganaderos grandes. Los propietarios de los hatos más grandes fueron desplazados en una escala mucho menor que los ganaderos más pequeños. Por el contrario, tanto el homicidio como la amenaza disminuían en relación al tamaño del hato, al igual que las formas más directas de violencia: el abuso físico y sexual, la tortura y el reclutamiento forzado. Los grandes ganaderos declararon cuatro veces más que los pequeños ser víctimas de extorsión. El secuestro extorsivo, igualmente, fue reportado casi siete veces más por los grandes que por los pequeños ganaderos. De la misma manera, los grandes ganaderos parecen tener más encuentros con grupos armados, pues el 7,3\% de ellos declararon ser víctimas de cuatro o más crímenes por parte de beligerantes (las cadenas de crímenes más recurrentes son el secuestro y la extorsión $(8,5 \%)$ o la extorsión y la amenaza (6,1\%)). El 43,1\% de los pequeños ganaderos, por su parte, solo informaron un hecho, siendo los más frecuentes el desplazamiento (14,7\%), el asesinato $(12,8 \%)$ o la pérdida de sus rebaños y ser desplazados $(11,9 \%)$.

Como se esperaba, en su mayoría, los crímenes tienen alguna relación con la sustracción forzosa de recursos por parte de los actores armados. Aquí, el tamaño del hato parece tener cierto poder explicativo. Los pequeños ganaderos, al no contar con recursos suficientes, se vieron forzados a abandonar la región luego de perder sus animales y recursos. En cambio, los ganaderos que contaban con operaciones lo suficientemente grandes como para mantenerse a flote y producir ganancias teniendo

9. Al considerar los resultados del modelo dos individualmente, se ve que existe una relación significativa entre crímenes contra ganaderos y presencia de las AUC. Si bien esta relación no se presente en todos los modelos, ello podría entenderse de dos maneras: las AUC hacen presencia en municipios con altos índices de afectación contra los ganaderos o impulsan el escalamiento en las tasas de criminalidad contra el gremio. Sin embargo, al estimar una regresión con series temporales, se comprobó que, si bien la presencia de las AUC reduce la incidencia de crímenes contra los ganaderos con el paso del tiempo, esta relación no es significativa; es decir, los ganaderos no se vieron protegidos, necesariamente, por los grupos de autodefensa.

10. La base de datos incluye una variable que califica a cada productor de acuerdo al número de animales que posee: muy pequeño, <10; pequeño, 11-25; mediano/pequeño, 26-50; medio, 51-100; mediano/grande, 101-250; grande, 251-500; grande medio, 501-1000; muy grande, >1000. Para el propósito de este estudio, se redujeron las ocho categorías en tan solo tres: pequeño $(<10-50)$, medio ( $51-250)$ y grande $(>251)$. 
en cuenta la "vacuna ganadera" entre sus cálculos, pudieron quedarse en la zona. La población restante, aquellos ganaderos que cuentan con algunos recursos, pero que no pueden comprometerlos ante los avatares de la guerra y decidían quedarse, se vieron forzados a resolver un dilema: ¿cómo enfrentar la captación forzosa de recursos por parte de los grupos armados? A continuación, una reseña de cuatro principales estrategias, de acuerdo al estudio cualitativo de los testimonios.

1. “Cooperar” o “colaborar”. Cuando los guerrilleros tomaron el control del altiplano de Túquerres (Nariño), relata un pequeño ganadero de la región, "empezamos a asustarnos, a tomar las debidas precauciones y a aprender a defendernos (...) porque no habíamos vivido esa experiencia". Aprender a vivir bajo el régimen de los grupos armados es uno de los temas recurrentes en las narrativas de los ganaderos. En tiempos de crisis, estos tenían que aprender estrategias básicas de supervivencia, tales como disparar un arma o administrar sus fincas por radioteléfono, saber qué tiempos eran buenos para movilizarse o cuáles eran las mejores rutas. Sin embargo, lo más importante era aprender con quién (y con quien no) hablar, cómo y cuándo.

A fin de continuar con el transcurso de sus vidas, muchos ganaderos tuvieron que aprender a colaborar. Colaborar o cooperar, en el registro de la práctica cotidiana de los ganaderos no es ayudar a los actores armados de acuerdo a algún tipo de afinidad ética o política, sino que refiere al actuar sin oponerse al orden beligerante. En el contexto de la captación de recursos, colaborar implica cancelar la suma demandada por el grupo armado, bien sea directamente por el ganadero o sus familiares, o indirectamente a través del mayordomo o el contador de la finca. En el caso de la extorsión simple (la "vacuna ganadera”), las sumas eran determinadas por el número de hectáreas o por cabeza de ganado ${ }^{11}$. En el caso del secuestro extorsivo, de acuerdo con el nivel económico de sus víctimas y familiares. No todos los ganaderos pudieron colaborar, pues ello implicaba disponer de recursos económicos. Al verse en la necesidad de utilizar sus recursos, la mayoría de los ganaderos entrevistados decidió abandonar sus predios y buscar fortuna en la ciudad. Para los que se quedaban, el resultado de esta estrategia fue la instauración de una relación tributaria paraestatal que les aseguraba a los ganaderos-así fuera por un tiempo limitado-que el grupo armado no iba a cometer un crimen contra ellos.

Hubo varias razones por las cuales los ganaderos decidieron cooperar. Primero, los relatos demuestran que esta fue, ante todo, una decisión pragmática: se apoya al grupo extorsivo para reducir el riesgo. $\mathrm{O}$, en términos de un ganadero del sur del

11. Las sumas declaradas suelen variar en relación con el tiempo y la región, mas no necesariamente en cuanto al grupo armado. A 2018, se estima que el precio por Ha es de 10 ooo COP y por cabeza de ganado, 500o COP. 
Cesar: "yo para sobrevivir en silencio, apoyo". Del mismo modo, se argumenta que, ante la falta de presencia estatal, la cooperación era la única alternativa. Narrativas sobre el abandono del Estado también son usadas para explicar la cooperación como una necesidad a la hora de establecer algún tipo de orden local. La disposición de la comunidad hacia los grupos armados fue, además, una de las razones que influyeron en la decisión de cooperar a nivel individual. Algunos lo hicieron por miedo: varios ganaderos argumentaron que en sus comunidades había redes de informantes financiadas por los grupos armados a fin de mantenerlos al tanto de las opiniones y ocurrencias locales. Un fragmento de la entrevista realizada, a mediados de 2013, a un ganadero en Caquetá amplía:

(Las FARC) es una industria en San Vicente, la guerrilla da empleos (...) tiene muchos seguidores que cobija con la manta de ellos. Mucho trabajador, mucho finquero, mucho testaferro, mucho comerciante (...) un séquito de gente que hace seguimiento a (lo que uno hace). Entonces la guerrilla es como una religión en ese pueblo (Ganadero, comunicación personal, 2013).

Los testimonios también tienden a señalar que la decisión de cooperar fue tomada de forma colectiva entre los ganaderos de la zona. Esto explicaría muy bien por qué las directivas de entidades que facilitan el encuentro y deliberación gremial, tal como el Fondo Ganadero de Córdoba o la Asociación Campesina de Ganaderos y Agricultores del Magdalena Medio, se vieron implicados en la participación, expansión y financiación de las AUC. "Hoy en día todo mundo sataniza a los paramilitares", sostiene un ganadero grande del Cauca al narrar la llegada del Bloque Calima, "pero nos olvidamos en que hubo un momento en que la situación era tan agobiante que todo mundo apoyaba a los paramilitares o al menos estaba de acuerdo". Testimonios de este orden revelan que cómo actuar ante el dilema de la captación de recursos es un problema que también encuentra respuesta en los procesos comunitarios, locales y regionales.

Esto no quiere decir que no hubiese colaboradores y simpatizantes del bando opuesto dentro de sus comunidades y espacios de deliberación gremial. En su testimonio, un ganadero medio de Villanueva se refirió a los colaboradores como "vividores" que incentivaron la guerra e hicieron de ella un negocio. En Norte de Santander, un ganadero relató cómo el ELN tomó posesión de un conjunto de fincas y las redistribuyó entre quienes los apoyaban: "son profesionales en eso". En Sucre, algunos ganaderos explicaron que, tras la llegada de sectores asociados al narcotráfico y al proyecto paramilitar, las AUC cambiaron su rumbo y "terminaron (...) cubriéndoles el corredor de droga a los narcotraficantes por aquí por el Morrosquillo". A diferencia de los ganaderos que solamente colaboran, aquellos que apoyan a la 
organización y se benefician de sus acciones son descritos por sus pares como personas carentes de principios éticos, con intereses ocultos o ajenos a su comunidad.

Para los que pudiesen ajustarse económicamente a la demanda de la "vacuna", la colaboración fue la estrategia más efectiva, pero, en algunos casos, también resultó ser la más costosa. Durante el período 1996-2002 -el momento más crítico de escalamiento de la guerra-, los órdenes locales se vieron drásticamente transformados. Quienes en algún momento colaboraron ávidamente con un bando fueron tratados como un objetivo militar por el otro. De acuerdo a los testimonios, durante este período los homicidios y el desplazamiento de los ganaderos fueron justificados por los actores armados, al tildarlos de ser simpatizantes o colaboradores directa o potencialmente del bando opuesto. Cuando el Bloque Norte de las AUC llegó a Chiriguaná (Cesar), por ejemplo, los paramilitares citaron a los ganaderos en un quiosco de la feria. Un comandante llamado Harold -afirma uno de los asistentes a esta reunión- tenía una lista de las personas que le colaboraban a la guerrilla y empezó a leerla. Un prominente ganadero de la región se puso de pie y respondió "anótame a mí y a todos los que estamos aquí, porque usted no puede desconocer que a todos nos ha tocado colaborar de alguna u otra manera (...) ¿no ve que nosotros convivimos con la guerrilla veinte años?”.

2. Negociar. De los testimonios se entiende que la cooperación es una estrategia costosa y difícil de mantener en el tiempo. Los ganaderos que declararon haber negociado el precio de la "vacuna ganadera" dijeron haberlo hecho en aquellos casos en que los recursos eran escasos o en que la suma demandada comprometía la producción o su capacidad para actuar en otros campos de la vida social. Aquí, ganaderos y actores armados se veían obligados a participar en el reconocimiento mutuo de sus capacidades coercitivas y financieras, respectivamente, a fin de redefinir la demanda. Por lo general, quienes colaboraban tuvieron que renegociar su contribución a las organizaciones beligerantes en algún momento. En Antioquia, un ganadero prominente fue secuestrado por el ELN, quien exigió 1500 ooo USD por su liberación. Si bien se desconoce la naturaleza o duración de las negociaciones, la suma que finalmente se pagó fue de 84 ooo USD, luego de que los guerrilleros fueran informados de que los bienes que creían estaban a su nombre eran propiedades conjuntas y, por lo tanto, no podían ser vendidas en el tiempo esperado.

Dependiendo de las circunstancias, la suma también podía canjearse por una amplia gama de recursos, como cabezas de ganado, alimentos, ropa, trabajo en la construcción, conducción de un automóvil o préstamo de una propiedad. Aquí no solo los recursos económicos, sino también el capital social, se convertían en factores determinantes. A su llegada a la región del sur de Nariño, los paramilitares 
del Frente Libertadores del Sur aceptaban dinero o información. En San Alberto (Cesar), el ELN pedía a los ganaderos que emplearan a sus militantes. Un ganadero mediano del Tolima reconoció que, a mediados de los noventa, en vez de pagar la vacuna entregó algunos rifles. A su vez, otro ganadero mediano en Barrancas (Cesar) negoció su vacuna, paradójicamente, por cien dosis de vacuna antitetánica. Al haber estudiado medicina, su profesión le permitió obtener la mayor parte de ellas, pero tuvo que pedirles a varios de sus amigos que compraran algunas dosis, pues no quería "escandalizar" a los boticarios locales con la situación. En una negociación, todo depende de las necesidades y capacidades mutuas.

La negociación también da cabida al uso de diferentes estrategias por parte de los ganaderos, a fin de persuadir a sus victimarios. En el testimonio que abre este artículo, por ejemplo, Diana explica cómo aprendió a llorar, pues sabía que ello podía hacerle entender a los captores que la suma que estaba ofreciendo era todo lo que podía pagar. A veces implicaba ir a hablar con el comandante, afianzar su lealtad, presentar un buen argumento o, a veces, hacerles entender que la producción no fue buena. Sin embargo, los testimonios dan a entender que los grupos armados son quienes tenían el control en el proceso de negociación, pues podían aceptar o rechazar la oferta e, incluso, aumentar los costos. Después de llevarse su ganado a cambio de la vacuna-recuerda un ganadero grande en Santander-, cerca de ochenta hombres de las AUC llegaron a su finca y este se vio en la obligación de hospedarlos y darles de comer. Aunque no tenía los recursos para hacerlo, cree que haberse negado podría haberle salido mucho más caro.

Los vínculos políticos, sociales y familiares son fundamentales para determinar qué, cómo y cuándo negociar. En municipios controlados por las FARC, de acuerdo a los testimonios, conocer a una figura en el poder (el juez, el comandante, el oficial de policía, el candidato político) no siempre era útil a la hora de negociar. Sin embargo, tener contactos con un miembro de la estructura armada, sí. Cuando Augusto -un ganadero de La Plata (Huila)- fue secuestrado por la guerrilla, el mayordomo de su finca, quien había sido estudiante de la escuela donde el comandante local había enseñado antes de enlistarse, intercedió a nombre de la familia. Aunque esa conexión no garantizaba la liberación, sí le dio a la familia unos días más para recolectar el dinero. De forma similar, durante la expansión del Bloque Norte hacia el sur del Cesar, demostrar tener algún tipo de relaciones entre "reconocidos empresarios" y ganaderos locales fue estratégico para determinar la filiación política del ganadero. A este tipo de capital podría llamársele "capital social beligerante": conexiones con individuos que podrían influir en el curso de la guerra como aliados, simpatizantes, militantes o enemigos. 
3. Postergar. Los ganaderos también podían tomar una medida más riesgosa:postergar su compromiso. Como táctica de los ganaderos, postergar se refiere a una serie de prácticas que van desde no responder a una llamada telefónica, tomar días extra para pagar, abandonar el municipio por un tiempo o, simplemente, esconderse. Postergar es extender la resolución del dilema hasta que algo (la llegada del Ejército o la venta de un ganado, por ejemplo) cambie las condiciones en que este ha sido formulado. Durante el período aquí estudiado, varios ganaderos declararon haber administrado sus fincas por teléfono o radio, o haberlas visitado con menos frecuencia; prefirieron viajar de día y no pasar la noche en la propiedad; cambiaron sus números de teléfono; enviaron parientes y conocidos a supervisar; o se reunieron con el gerente de la finca en un paraje cercano. También evitaban ser identificados. Muchos ganaderos utilizaron diferentes estrategias, como pedir automóviles prestados, conducir por caminos de herradura o vestirse de forma diferente cuando visitaban sus fincas. Engañar al enemigo es uno de los subtemas que surge en los testimonios que giran en torno a la táctica de postergar, ya que los actores armados podían identificar a los ganaderos por su nombre, pero no siempre les resultaba fácil reconocerles físicamente. El relato de Aquiles, en Norte de Santander, ilustra sobre este tema:

Antes del 2001 (...) limitaba mis visitas a la finca San Lorenzo, donde seguía con mis prácticas campesinas y de trabajo fuerte (...). Precisamente fue allí, en una de las tantas jornadas de trabajo, arrancando maciega y dando rula en compañía de “Toñito” Fonseca y otros dos trabajadores, llegaron a la finca en sendas motos un par de guerrilleros (...). Después de un cortés saludo, nos preguntaron: “'Han visto a Don Aquiles?”. "Don Aquiles se quedó en la casa”, les respondió “Toñito” Fonseca. Para mi fortuna, era claro que los guerrilleros no me conocían (Aquiles, comunicación personal).

La información es un recurso fundamental a la hora de recurrir a esta táctica. Cuando un ganadero había colaborado previamente con un grupo armado, y ambas partes tenían información completa sobre el curso de acción y las expectativas, lo más seguro es que el actor armado intentara forzar la colaboración de una u otra forma. Sin embargo, cuando el postergar ocurría en un escenario donde la información era incompleta, la situación estaba a favor del ganadero. Luis Alberto, ganadero del Cesar, hizo un negocio con su primo Raúl, quien le entregó en pago 300 animales marcados con su hierro. Los miembros de la AUC notaron la entrada del ganado y planearon llevárselo en la madrugada. Las AUC estaban extorsionando a Luis Alberto, pero no a Raúl. Sin embargo, Luis Alberto se enteró del plan y, con la ayuda de su mayordomo, regresó y escondió los animales en la finca de Raúl durante la noche. "Las armas más grandes de la guerrilla no son sus rifles", declara un peque- 
ño ganadero de Caquetá, "sino su capacidad para reconocer (a los miembros de la comunidad)". Como fuerzas extranjeras, la falta de información beligerante juega en beneficio de los ganaderos.

Si bien el postergar la interacción puede dar un poco de ventaja al ganadero, la demora también acarrea un alto costo. De acuerdo a los testimonios, los ganaderos que recurrieron a esta táctica de forma recurrente se vieron afectados no solo por el actuar vengativo de los actores armados -en caso de ser identificado como un desertor o un doble agente-, sino por los costos extra que debían asumir -tal como invertir en nuevas tecnologías, pagar más a sus trabajadores, descuidar la finca, evitar créditos o hacer inversiones-. Igualmente, postergar podía ser entendido como una ofensa al orden beligerante y las consecuencias podían llegar a ser fatales.

4. Negarse. Cuando los recursos no eran suficientes o no se podía disponer de ellos, solo quedaba negarse a cumplir la demanda del grupo armado. Para algunos ganaderos, esta era una decisión ética. Como sostiene Orlando, un pequeño ganadero de Puerto Libertador (Córdoba), al respecto de las demandas que las FARC ejercieron a mediados de los noventa y que le llevaron a abandonar sus propiedades en la vereda San Juan: "¿cómo iba yo a negociar con la guerrilla mi propia integridad personal? Yo no tengo precio, eso no es negocio...”. Para la mayoría de ganaderos en este estudio, en cambio, era la única alternativa para sobrevivir al orden beligerante.

Negarse, como una táctica para resolver el dilema de recursos, ocurría de dos maneras: resistiendo o renunciando. En cuanto a la primera, la base de datos de Fedegán incluye un reducido número de testimonios que dan cuenta de las experiencias de los ganaderos que se opusieron directamente y resistieron las formas de coacción de los grupos armados, en lugar de pagar la suma demandada. Esto se debe a que resistir era una opción muy arriesgada para los ganaderos, pues el equilibrio de fuerzas solía inclinarse a favor de las organizaciones beligerantes. Carlos, un ganadero mediano de Barrancabermeja, relata la respuesta que dio en 1998 a los miembros del ELN, cuando estos le exigieron entregarles su camioneta:

La camioneta no se las dejo, yo la compré, ustedes me dieron permiso para comprar una camioneta porque la otra era muy vieja y ya me la quemaron (...). Si la agarran a plomo, mátenme a mí, pero no me jodan la camioneta” Volteé y me volé, llegué a la bomba Yarima con la llanta pinchada y gasolina saliendo. A mí, desde esa época, el miedo ya se me ha pasado (Carlos, comunicación personal).

Resistir tiende a ser el primero o el último de los hechos reseñados por los ganaderos, pues al enfrentarse al dilema de los recursos, algunos preferían confrontar directamente a sus opresores y disputar su autoridad sin importar las consecuencias. 
Alfredo, un ganadero del Valle del Cauca, recuerda muy bien que las últimas palabras de su hermano fueron: "ustedes no me van a llevar", seguidas por tres disparos. El homicidio, como se esperaba, está fuertemente relacionado con esta estrategia. Sin embargo, eso no significa que no haya registro de casos en que la resistencia haya sido exitosa -al menos, en los términos de los ganaderos-. En Huila y Caquetá, la figura de Ismael Díaz Gaitán ocupa un lugar destacado en la memoria colectiva del gremio ganadero pues, desde principios de los noventa hasta el año 2003, Díaz Gaitán resistió a las demandas de las FARC contratando a un grupo de guardaespaldas fuertemente armado para que lo protegiesen a él y a su familia. En total, las FARC le robaron más de 4000 cabezas de ganado e intentaron matarlo nueve veces, antes de su muerte a finales de 2003 (aún se desconocen las circunstancias). Igualmente, figuras polémicas como Salvatore Mancuso o Rodrigo Tovar (en sus primeros años) ocupan un lugar privilegiado en la memoria de los ganaderos de la región Caribe, pues estos jefes paramilitares son descritos en los testimonios como hombres "buenos", "conciliadores", "conocidos", "inquietos" que buscaban solucionar los problemas que afectaban al gremio.

Quienes podían resistir, se deduce de los testimonios, hacían un cálculo en relación con dos variables: la presencia de una organización capaz de brindarles protección (el ejército o los paramilitares), y la presencia de una red de apoyo local. Si el ganadero lograba obtener protección de otra organización podía invertir el equilibrio de poder y resistir la demanda por completo. Sin embargo, esto requería un importante capital económico o social, bien fuera organizando su propia estrategia de defensa o convenciendo a algún bando de llegar a la región. Del mismo modo, si la resistencia ocurría en términos de una acción colectiva, los ganaderos tenían mayores posibilidades de garantizar su seguridad de manera conjunta, pues no solo se reducían los costos de "traer" una nueva organización, sino de minimizar el riesgo y actuar en bloque.

Como se discutió anteriormente, los testimonios de los ganaderos dejan entender que detrás de la financiación y el apoyo colectivo a los grupos de autodefensa, por ejemplo, había una necesidad de resistir el excesivo de cobro de vacunas por parte de los grupos guerrilleros. En términos de Manuel, ganadero del Putumayo: "llegaron las autodefensas y eso acabó hasta con el nido de la perra". A diferencia de las guerrillas, las AUC se identificaron en un principio como "una avanzada anticomunista en la defensa de la propiedad privada y la libre empresa" (Romero, 2002: 287), centrándose en la consolidación de la soberanía política y económica en y para las regiones afectadas. No obstante, el modus operandi de las AUC era mucho más que una organización de autodefensa. 
A pocos meses de su formación, las AUC iniciaron una agresiva campaña contra los bastiones de las FARC y el ELN, cometiendo una cantidad sin precedentes de violaciones de los Derechos Humanos, incluso contra el sector ganadero. Para los que no resultaron afectados, apoyar al bando opuesto solía ser, simplemente, un cambio en los actores, pues el financiamiento y apoyo a estos terminaba reformulando el dilema de la captación de recursos. "Si los (grupos armados) cobraban $\$ 10$ ooo por hectárea en ese momento", se pregunta un ganadero del Cesar, "y los paramilitares piden la misma suma por proteger a la gente (...) ¿de qué sirve una 'buena causa'?". Así, la resistencia a través del apoyo a una organización rival reiniciaba el ciclo de violencia relacionado con la dominación territorial y, como lo revelan los datos de Fedegán, los ganaderos terminaron severamente afectados por ello al cabo de los años.

Finalmente, el ganadero podía renunciar, negarse a participar y abandonar el contexto en que se formulaba el dilema, como se ha insistido, en forma de desplazamiento. Esta es la táctica más recurrente dentro del repertorio ganadero. Los primeros en renunciar son los pequeños ganaderos que, luego de perder sus animales o cuando no tenían recursos ni opciones disponibles, abandonaban la zona. Sin embargo, también fue una táctica empleada por un número importante de grandes ganaderos que, debido a sus condiciones materiales, podían migrar a la ciudad mientras se desarrollaba la confrontación. Muchas haciendas grandes en el país fueron abandonadas por décadas y sus dueños cambiaron de profesión o de vida, mientras se restablecían las condiciones de seguridad. Aunque esta táctica tendía a ser efectiva a la hora de preservar la vida, también solía poner en riesgo no solo las propiedades, sino el predio mismo. Los ganaderos con menores recursos que recurrieron a esta táctica, en su mayoría, lo perdieron todo.

\section{Conclusiones}

Los estudios sobre la participación de los ganaderos en la confrontación armada tienden a recurrir a dos tipos de narrativas. Por un lado, se encuentran aquellos que se enfocan en entender sus vínculos con los actores armados, reduciéndolos a un grupo de predadores con una serie de intereses económicos y políticos claros en su accionar. Por otro lado, están aquellos que recurren a lo que el historiador guatemalteco Arturo Taracena (2007) describe como la teoría del "gran sándwich": civiles atrapados en medio de una confrontación brutal entre dos campos en conflicto, víctimas pasivas sin capacidad para intervenir en el curso de la guerra. Al explorar las lógicas detrás de las interacciones entre ganaderos y los grupos alrededor de la captación forzosa de recursos, este artículo demuestra cómo los ganaderos fueron actores estratégicos 
a la hora de tomar decisiones, recurrir a capitales sociales, culturales y económicos, para así negociar los términos de su propio sometimiento.

Este artículo también señala cómo la disponibilidad de recursos es un factor determinante para el entendimiento de las dinámicas de la violencia. Como se ha expuesto, los ganaderos que no podían disponer fácilmente de sus recursos o dependían de economías frágiles fueron víctimas de violencia contra su integridad o forma de vida en mayores proporciones que aquellos que contaban con más recursos. A su vez, los civiles que tenían más recursos podían colaborar con los actores armados y reducir el riesgo de ser atacados. Aun así, el artículo también muestra que la captación forzosa de recursos es un proceso complejo. Colaborar no siempre es la mejor estrategia, y de allí que los ganaderos se vean en la necesidad de negociar, postergar o negarse.

Con esto no se quiere desconocer la participación de sectores ganaderos en la organización, financiación y expansión de grupos paramilitares (Ronderos, 2014) o pasar por alto el hecho de que la guerrilla de las FARC declarase al gremio como un objetivo militar (Aguilera, 2013). Más bien, se quiere reiterar que, en el transcurso cotidiano del conflicto armado, hubo más opciones que apoyar o resistir. Las guerras son tiempos de efervescencia social, en las que la violencia política se privatiza y se moviliza en los contextos locales (Kalyvas, 2006). Por ende, el estudio sobre los vínculos y prácticas ocurridas en el marco de la confrontación armada implica no solo entender la compleja interacción entre las lógicas políticas, económicas y territoriales, sino un compromiso metodológico con el entendimiento de los contextos locales en su incertidumbre, cambio y constante reajuste.

Para los estudios sobre la construcción de la memoria histórica, además, este es un llamado importante a explorar los matices de las texturas cotidianas en que ocurre la violencia, los cuales desbordan las teodiceas sacralizadas e institucionalizadas con que se ha venido dando sentido al dolor social. Reconocer y documentar estas disposiciones individuales es esencial para el desarrollo de cualquier agenda investigativa interesada en la construcción de una memoria inclusiva, pues en nuestra capacidad de reconfigurar nuestras categorías y modos de análisis, redefinimos y damos complejidad a las narrativas sobre nuestro devenir común.

Finalmente, este artículo plantea dos desafíos para futuras investigaciones. Primero, los resultados reiteran que los ganaderos vieron a los grupos de autodefensa como una opción para repeler a sus victimarios, lo que sugiere la necesidad de estudiar a fondo el fenómeno paramilitar en sus propios términos: una solución a los problemas de orden local. Segundo, y en cuanto a una discusión sobre el paramilitarismo, es importante señalar que el gremio ganadero ha reconocido su responsabilidad ética -como atestiguan las narraciones- y reclaman no ser "demonizados" 
por recurrir a lo que en ese momento parecía ser la única solución. No obstante, es importante continuar con el trabajo investigativo sobre concentración de tierras y expansión del hato ganadero, desglosando el modo y el tipo de producción ganadera, e identificando aquella que se ha visto beneficiada y aquella que se ha visto perjudicada por la confrontación armada en Colombia.

\section{Referencias}

Aguilera, Mario (2013). Guerrilla y Población Civil. Trayectoria de las FARC 1949-2013. Bogotá: IEPRI/CNMH.

Aparicio, Juan Ricardo (2016). Del archivo y la construcción del territorio: una problematización de los estudios de memoria. En Monika Contreras; Tatjana Louis; Stefan Rinke (eds.), Memoria y conflicto. Memorias en conflicto: intercambios metódicos y teóricos de experiencias locales latinoamericanas (pp. 54-73). Stuttgart: Verlag Hans-Dieter Heinz/Akamedischer Verlag Stuttgart/Universidad de los Andes.

Arjona, Ana (2015). Civilian Resistance to Rebel Governance. En Ana Arjona, Nelson Kasfir y Zachariah Mampilly (eds.), Rebel Governance in Civil War (pp. 180-200). Cambridge, Mass.: Cambridge University Press.

Auyero, Javier (2007). Routine Politics and Violence in Argentina: The Gray Zone of State Power. Cambridge, UK/New York: Cambridge University Press.

Barón, Luis Fernando (2016). «Se nos salió de las manos...». Memorias de empresarios sobre el conflicto armado en el Valle del Cauca. Tabula Rasa, 24, 263-301.

Blair, Elsa; Grisales Hernández, Marisol; Muñoz Guzmán, Ana María (2009). Conflictividades urbanas vs. «guerra» urbana: otra «clave» para leer el conflicto en Medellín. Universitas Humanistica, 67, 29-54.

Bolívar, Ingrid Johanna; Nieto, Lorena (2003). Supervivencia y regulación de la vida social: la política del conflicto. Nómadas, 19, 78-87.

Campuzano, Ramiro (2013). Paramilitarismo y vida cotidiana en San Carlos (Antioquia): etnografía desde una antropología de la violencia. Boletín de Antropología, 28(45), 130-153.

Collier, Paul; Hoeffler, Anke; Rohner, Dominic (2009). Beyond Greed and Grievance: Feasibility and Civil War. Oxford Economic Papers, 61, 1-27.

Collier, Paul; Sambanis, Nicholas (2005). The Collier-Hoeffler Model of Civil War Onset and the Case Study Project Research Design. En Paul Collier; Nicholas Sambanis (eds.), Understanding Civil War: Evidence and Analysis. Vol. 1 (pp. 1-33). Washington, DC: World Bank Publications. 
Espinosa, Nicolás (2010). Política de vida y muerte: etnografía de la violencia diaria en la Sierra de la Macarena. Bogotá: ICANH.

Flórez-Malagón, Alberto (2008). Introducción. En El poder de la carne: Historias de ganaderías en la primera mitad del siglo XX en Colombia (pp. 10-26). Bogotá: Pontificia Universidad Javeriana.

Grupo de Memoria Histórica (2013). iBastaya! Colombia: memorias de guerray dignidad. Bogotá: Imprenta Nacional.

Guber, Rosana (2001). La etnografia: método, campo y reflexividad. Bogotá: Editorial Norma.

Gutiérrez-Sanín, Francisco; Vargas, Jenniffer (2017). Agrarian Elite Participation in Colombia's Civil War. Journal of Agrarian Change, 17(4), 739-748. https://doi.org/10.1111/joac.12235

Guzmán Campos, Germán; Fals Borda, Orlando; Umaña Luna, Eduardo (1962). La violencia en Colombia: estudio de un proceso social. Bogotá: Tercer Mundo.

Hazen, Jennifer (2013). What Rebels Want: Resources and Supply Networks in Wartime. Ithaca, NY: Cornell University Press.

Hristov, Jasmin (2014). Paramilitarism and Neoliberalism: Violent Systems of Capital Accumulation in Colombia and Beyond. London: Pluto Press.

Idrobo, Nicolás; Mejía, Daniel; Tribin, Ana María (2014). Illegal Gold Mining and Violence in Colombia. Peace Economics, Peace Science and Public Policy, 2o(1), 83-111. https://doi. org/10.1515/peps-2013-0053

Jaramillo-Marín, Jefferson (2014). Pasadosy presentes de la violencia en Colombia: estudios sobre las comisiones de investigación (1958-2011). Bogotá: Pontificia Universidad Javeriana.

Jimeno, Myriam; Varela, Daniel; Castillo, Ángela (2012). Experiencias de violencia: etnografía y recomposición social en Colombia. Sociedade e Cultura, 14(2), 275-285. https://doi. org/10.5216/sec.v14i2.17604

Kalyvas, Stathis (2006). The Logic of Violence in Civil War. Cambridge: Cambridge University Press.

Kaplan, Oliver (2017). Resisting War: How Communities Protect Themselves. Cambridge: Cambridge University Press.

Levi, Primo (2005). Trilogía de Auschwitz. Madrid: El Aleph.

Madariaga, Patricia (2006). Matan y matan y uno sigue ahí: control paramilitary vida cotidiana en un pueblo de Urabá. Bogotá: Universidad de los Andes.

Prieto Sanabria, Juan Diego (2012). Guerras, pacesy vidas entrelazadas. Coexistencia y relaciones locales entre víctimas, excombatientes y comunidades en Colombia. Bogotá: Universidad de los Andes. 
Programa de las Naciones Unidas para el Desarrollo Colombia (2010). Huila: análisis de la conflictividad. Bogotá: PNUD Colombia.

Ramírez, María Clemencia (2011). Between the Guerrillas and the State: The Cocalero Movement, Citizenship, and Identity in the Colombian Amazon. Durham, NC: Duke University Press.

Rees, Tobias (2018). After Ethnos. Berkeley: University of California Press.

Restrepo, Jorge; Spagat, Michael; Vargas, Juan (2003). The Dynamics of the Colombian Civil Conflict: A New Data Set (SSRN Scholarly Paper No. ID 480247). Rochester, NY: Social Science Research Network. Recuperado de https://papers.ssrn.com/abstract $=480247$

Rettberg, Angelika; Leiteritz, Ralf; Nasi, Carlo; Prieto, Juan Diego (2018). ¿Diferentes recursos, conflictos distintos? La economía política regional del conflicto armado y la criminalidad en Colombia. Bogotá: Universidad de los Andes.

Romero, Mauricio (2000). Changing Identities and Contested Settings: Regional Elites and the Paramilitaries in Colombia. International Journal of Politics, Culture, and Society, 14(1), 51-69. https://doi.org/10.1023/A:1007861013044

Romero, Mauricio (2002). Democratización política y contrarreforma paramilitar en Colombia. Política y Sociedad, 39(1), 273-292.

Ronderos, María Teresa (2014). Guerras recicladas. Bogotá: Penguin Random House.

Sánchez, Gonzalo (2003). Guerras, memoria e historia. Bogotá: ICANH.

Sánchez, Gonzalo (2018). Reflexiones sobre genealogía y políticas de la memoria en Colombia. Análisis Político, 31(92), 96-114.

Sánchez-León, Nelson Camilo; Payne, Leigh; Pereira, Gabriel; Bernal-Bermúdez, Laura; Marín-López, Daniel; Barboza-López, Miguel (2018). Cuentas claras: el papel de la Comisión de la Verdad en la develación de la responsabilidad de empresas en el conflicto armado colombiano. Bogotá: Dejusticia.

Sarmiento, Christian; Aviles, Edgar (2012). Acumulación capitalista y nueva espacialidad en el Magdalena Medio. Ciencia Política, 7(13), 6-39.

Serna-Dimas, Adrián (2012). Memoria y creencia: una mirada políticamente incorrecta a ciertas vindicaciones de la memoria. En Las víctimas: entre la memoria y el olvido (pp. 66-80). Bogotá: Instituto para la Pedagogía, la Paz y el Conflicto Urbano/Universidad Distrital Francisco José de Caldas.

Taracena-Arriola, Arturo (2007). La experiencia de un historiador en la Comisión de Esclarecimiento Histórico de Guatemala. En Anne Pérotin-Dumon (comp.), Historizar el pasado vivo en América Latina (pp. 1-21). Recuperado de http://www.historizarelpasadovivo.cl/ downloads/taracena.pdf

Uribe, María Victoria (1992). Limpiar la tierra: guerra y poder entre esmeralderos. Bogotá: CINEP. 
Uribe de Hincapié, María Teresa (2001). Nación, ciudadanoy soberano. Medellín: Corporación Región.

Van Ausdal, Shawn (2009). Potreros, ganancias y poder. Una historia ambiental de la ganadería en Colombia, 1850-1950. Historia Crítica, 39, 126-149.

Vásquez, Teófilo (2006). Dinámica, tendencias e interacciones de los actores armados en el Magdalena Medio. 1990-2001. En Mauricio Archila; Ingrid Bolívar; Álvaro Delgado; Martha Cecilia García; Fernán González; Patricia Madariaga; Teófilo Vásquez (comps.), Conflictos, poderes e identidades en el Magdalena Medio, 1990-2001 (pp. 313-372). Bogotá: CINEP.

\section{Anexos}

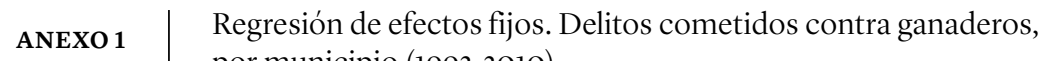
por municipio (1993-2010)

\begin{tabular}{|c|c|c|c|c|}
\hline & (1) & (2) & (3) & \\
\hline Índice de ruralidad & $\begin{array}{c}-0,935^{* * *} \\
(-3,87)\end{array}$ & $\begin{array}{c}-0,603^{* *} \\
(-3,29)\end{array}$ & $\begin{array}{c}-2,289^{* * *} \\
(-3,61)\end{array}$ & $\begin{array}{c}-2,183^{* * *} \\
(-3,47)\end{array}$ \\
\hline Necesidades básicas insatisfechas & $\begin{array}{c}-0,00133 \\
(-0,55)\end{array}$ & & $\begin{array}{c}-0,0100 \\
(-1,92)\end{array}$ & $\begin{array}{c}-0,00798 \\
(-1,50)\end{array}$ \\
\hline Número de cabezas de ganado & $\begin{array}{c}0,108^{* * *} \\
(4,58)\end{array}$ & & $\begin{array}{c}0,139^{* *} \\
(2,88)\end{array}$ & $\begin{array}{c}0,140^{* *} \\
(2,96)\end{array}$ \\
\hline Distancia a mercado mayorista & $\begin{array}{c}0,226^{* * *} \\
(3,81)\end{array}$ & & $\begin{array}{c}0,208^{*} \\
(2,11)\end{array}$ & $\begin{array}{c}0,204^{*} \\
(2,12)\end{array}$ \\
\hline Presencia de AUC & & $\begin{array}{c}0,470^{* * *} \\
(4,42)\end{array}$ & & $\begin{array}{c}0,0420 \\
(0,37)\end{array}$ \\
\hline Presencia de ELN & & $\begin{array}{c}0,206^{* * *} \\
(3,88)\end{array}$ & & $\begin{array}{l}0,128 \\
(1,48)\end{array}$ \\
\hline Presencia de FARC & & $\begin{array}{c}0,0439 \\
(1,29)\end{array}$ & & $\begin{array}{c}-0,0506 \\
(-0,36)\end{array}$ \\
\hline Índice de conflicto & & $\begin{array}{c}\mathrm{O}, \mathrm{O} 2 \mathrm{O} 3 \\
(1, \mathrm{O} 1)\end{array}$ & & $\begin{array}{c}-0,406^{* * *} \\
(-4,06)\end{array}$ \\
\hline Número de homicidios (log) & & & $\begin{array}{l}0,0251 \\
(0,45)\end{array}$ & $\begin{array}{c}0,0753 \\
(1,29)\end{array}$ \\
\hline Número de secuestros (log) & & & $\begin{array}{c}0,394^{* *} \\
(3,27)\end{array}$ & $\begin{array}{c}0,396^{* * *} \\
(3,31)\end{array}$ \\
\hline Número de desplazamientos (log) & & & $\begin{array}{c}0,328^{* * *} \\
(3,31)\end{array}$ & $\begin{array}{c}0,417^{* * *} \\
(3,98)\end{array}$ \\
\hline Constante & $\begin{array}{c}-1,858^{* *} \\
(-2,78)\end{array}$ & $\begin{array}{l}-0,544 \\
(-0,90)\end{array}$ & $\begin{array}{l}0,380 \\
(0,18)\end{array}$ & $\begin{array}{l}-0,867 \\
(-0,39)\end{array}$ \\
\hline $\mathrm{N}$ & 10159 & 18225 & 2830 & 2830 \\
\hline
\end{tabular}

Estadísticos t en paréntesis ${ }^{*} \mathrm{p}<0,05,{ }^{* *} \mathrm{p}<0,01,{ }^{* *} \mathrm{p}<0,001$ 